\title{
Biostimulative effect of amino acids and green algae extract on capsaicinoid and other metabolite contents in fruits of Capsicum spp.
}

\author{
Tilen Zamljen * ${ }^{*}$, Metka Hudina, Robert Veberič and Ana Slatnar
}

\begin{abstract}
Background: Biostimulants, such as algae extracts or amino acids, are becoming more common in agriculture because the mentality is to make plants more resistant or tolerant to negative environmental factors, rather than using synthetic chemicals (herbicides, insecticides and fungicides), whose use is decreasing year by year, forcing farmers and companies to develop new environmentally friendly products.

Results: In a field experiment, green algae and amino acids were tested as biostimulants on three hot pepper cultivars. A large variability was observed between the effects of the two biostimulants on the cultivars. Green algaetreated 'Somborka' and 'Habanero Red Caribbean' cultivars had 10\% and 5\% higher dry matter in seeds compared to control treatment. Total sugar content was negatively affected by green algae extract and amino acids in pericarp in cultivars 'Chili AS-Red' and 'Habanero Red Caribbean'. Total organic acids content was positively affected by amino acid treatment in 'Habanero Red Caribbean' pericarp and placenta, with an increase of $5.5 \mathrm{~g}$ and $2.1 \mathrm{~g} / 100 \mathrm{~g} \mathrm{DW}$, respectively. In terms of total phenolics, all three cultivars were positively affected by amino acid treatment, but not in each fruit part. In terms of capsaicinoid content, the greatest effect of the two stimulants was on 'Somborka', which varied from four (pericarp, seed) to 16 (placenta) times compared to the control. Amino acid extract decreased 'Habanero Red Caribbean' capsaicinoid content in placenta by about $40 \%$.

Conclusion: Amino acids were found to be superior to algal extract, although the effect of both was mostly cultivar specific. For a wider use of biostimulants, it should first be tested whether they are suitable for the cultivar in order to increase and optimize the results.
\end{abstract}

Keywords: Biostimulants, Capsaicinoids, Fruit quality, Organic acids, Sugar

\section{Introduction}

Chilies contain many health beneficial substances, such as capsaicinoids, which are known to have a positive effect on human health if consumed moderately $[1,2]$. Among the best known effects are increasing thermogenesis, which helps with weight loss, anti-carcinogenic

${ }^{*}$ Correspondence: tilen.zamljen@bf.uni-lj.si

Department of Agronomy, Biotechnical Faculty, University of Ljubljana, Jamnikarjeva 101, 1000 Ljubljana, Slovenia functions and improved cardiovascular health [3, 4]. Production of capsaicinoids in hot peppers is limited by many factors, including drought, insufficient light, salt stress and temperature $[5,6]$. All these factors can reduce the quality of chilies in terms of metabolites.

The impact of most of these environmental factors can be mitigated by the use of various substances that improve the condition of plants and help them to overcome stressful situations. There are several substances, including carbohydrate polymers, salicylic acid, methyl jasmonate, plant hormones, humic substances, etc. 
[7-10] that improved plant conditioning. Of the various plant biostimulants, amino acids and green algae extracts are also very commonly used in agriculture $[11,12]$.

Amino acids are very important in plant growth, development and metabolite synthesis, since they are the basic building blocks of proteins [11]. The synthesis of amino acids in plants is very energy consuming, so foliar application is a common practice in agriculture. Amino acids for foliar application are acquired by enzymatic hydrolysis from plant proteins (legumes) or animal protein hydrolysates [13]. With foliar application, the plant saves a lot of energy, since the amino acids are already formed and easily taken up to form protein hydrolysates and other metabolites.

Green algae are popular biostimulants, especially in ecological plant production. They can be grown with very few resources and contain significant amounts of amino acids, plant hormones, macro- and micro-nutrients, etc. [14]. Extracts from seaweeds contain several bioactive compounds that can act in plants resulting in positive physiological responses, such as improved biomass production, amelioration of nutrition and resistance to stress [15]. Algae are grown in open systems, such as ponds, bubble columns and stirred tanks [16]. Algae extracts are known to improve flowering, leaf and shoot growth, fruit set and yield, and also fruit quality $[12,15,17]$.

In our study, we used two commercially available biostimulants based on green algae and amino acids, respectively, on three Capsicum cultivars. Previous studies concentrated only on certain metabolites when applying amino acids and green algae extracts to chili plants. There is a lack of reports on the effect of green algae extracts on individual capsaicinoid contents. We tried to answer whether biostimulant treatments improve the quality of chili fruits and, if they do, how big is the impact on sugars, organic acids, phenolics and capsaicinoid contents. Metabolites were determined in different parts of the fruits. We also tried to discover whether the nitrogen from the two biostimulants impacts capsaicinoid accumulation, since every capsaicinoid molecule needs one nitrogen atom for its synthesis.

\section{Materials and methods}

\section{Experimental design}

The experiment was conducted in Ljubljana (latitude $46^{\circ} 3^{\prime} 4^{\prime \prime} \mathrm{N}$; longitude $14^{\circ} 30^{\prime} 18^{\prime \prime} \mathrm{E}$ ) at the Biotechnical Faculty, from 20th May to 30th September 2020. Three chili cultivars (C. annuum L. 'Chili-AS Rot'; $C$. annuum L. 'Somborka'; C. chinense Jacq. 'Habanero Red Caribbean' (purchased from Austrosaat). The seeds were sown in February and after the formation of the first leafs they were transplanted into $8 \mathrm{~cm}$ plastic pots. In May they were transplanted into the plastic greenhouse in silty loam soil. Irrigation and fertilization were conducted via a drip irrigation system, which was carried out daily, each plant receiving the same amount of water and fertilizer. On average, each plant received between 0.5 and 11 of irrigation water daily, depending on the temperature and stage of development of the plant. Fertilizer was applied four times during the experiment using a watersoluble NPK fertilizer (16:8:32) (Poly-Feed $^{\mathrm{TM}}$ ) with added micronutrients. Each plant received $200 \mathrm{mg} / \mathrm{l} \mathrm{N}$ at each fertilization. The average temperature in the greenhouse during the experiment was $23.8^{\circ} \mathrm{C}$.

Three treatments were applied: (i) bidistilled water as the control treatment; (ii) green algae (Phylgreen from Tradecorp International); and (iii) amino acids (Delfan Plus from Tradecorp International), each treatment consisting of four plants in three repetitions (12 plants for each treatment). The algae extract concentration in the algae treatment was $0.2 \%$ and the amino acid extract concentration was $0.1 \%$ in the amino acid treatment. Both treatment concentrations were based on the guidelines from the manufacturer. The green algae extract (Phylgreen) was extracted from Ascophyllum nodosum L. The specifications for the green algae extract were as follows: $15 \%$ dry matter, $0.2 \% \mathrm{~N}, 0.05 \% \mathrm{P}_{2} \mathrm{O}_{5}, 0.4 \% \mathrm{~K}_{2} \mathrm{O}, 8 \% \mathrm{C}$ and $1.2 \%$ mannitol. The $\mathrm{pH}$ ranged from 3.5 to 4.5 and the density was $1.1 \mathrm{~kg}$ per liter. The amino acid solution (Delfan Plus) is derived from animal protein hydrolysate and it contains $24 \%$ amino acids, $44.4 \%$ organic matter and $10.8 \%$ total nitrogen of which $6 \%$ was organic nitrogen, and $27.6 \%$ organic $C$. The $\mathrm{pH}$ level was 7.2.

All treatments were applied foliar, four times at 10-day intervals (16th July; 26th July; 5th August; 15th August). The first biostimulants were applied when the first fruits started to form and the plants were around one month old. For biochemical analysis, four to six randomly chosen fruits were harvested, amounting to 16 to 24 fruits for each cultivar in each treatment. Following Park, Lee [18], the fruits of 'Habanero Red Caribbean' and 'ChiliAS Red' were harvested when they had reached cultivar-specific color (red), were firm to the touch, and had a glossy appearance. The cultivar 'Somborka' was harvested at full size but not at a biologically mature stage, unlike the other two cultivars. 'Habanero Red Caribbean' was picked 50 days after fruit set, 'Chili-AS Red' was picked 35 days after fruit set and 'Somborka' 0 days after fruit set. The analysis of sugars and organic acids was performed on pericarp and placenta, and we also determined total phenolics and capsaicinoids in seeds.

\section{Dry matter evaluation}

Fruits were separated into three parts: pericarp, placenta and seeds. Every part was weighed before and after 
lyophilization, to calculate the dry matter. All data were expressed in \% of dry matter.

\section{Extractions and analysis}

\section{Sugars, organic acids and ascorbic acid}

The extraction and determination of individual sugars and organic acids were based on Zamljen, Jakopič [19]. Dry fruit samples $(0.05 \mathrm{~g})$ were extracted with $2 \mathrm{ml}$ of bidistilled water for sugars and organic acids and $4 \mathrm{ml}$ of $2 \%$ metaphosphoric acid for ascorbic acid. Samples were then placed on a shaker for $30 \mathrm{~min}$ at $300 \mathrm{rpm}$, and were then filtered through a $0.25-\mu \mathrm{m}$ cellulose filter (Chromafil A-20/25; Macherey-Nagel, Düren, Germany) and stored in vials at $-20{ }^{\circ} \mathrm{C}$.

The samples were analyzed on the Thermo Scientific Vanquish HPLC system (Thermo Scientific, San Jose, Calif., USA) with the use of IR (for sugars) and PDA detector (for organic acids and ascorbic acid). Sugar analysis was carried out using a Rezex RCM-monosaccharide column (Thermo Scientific, San Jose, USA) $(\mathrm{Ca}+2 \%)$ operated at $65{ }^{\circ} \mathrm{C}(300 \mathrm{~mm} \times 7.8 \mathrm{~mm})$ and, for organic acids and ascorbic acid, a Rezex ROA-organic acid $[\mathrm{H}+(8 \%)]$ column from Phenomenex Torrance, USA $\left(300 \mathrm{~mm} \times 7.8 \mathrm{~mm}\right.$ ) heated to $65{ }^{\circ} \mathrm{C}$ for organic acids and $20^{\circ} \mathrm{C}$ for ascorbic acid. All data were expressed in $\mathrm{mg} / 100 \mathrm{~g}$ dry weight (DW).

\section{Total phenolic content and capsaicinoids}

Powder $(0.05 \mathrm{~g})$ was extracted with $80 \%$ methanol. Samples were placed in a cooled ultrasonic bath $\left(0{ }^{\circ} \mathrm{C}\right)$ for $1 \mathrm{~h}$ and then centrifuged at $8000 \mathrm{rpm}$ for $6 \mathrm{~min}$ and filtered through a $0.25 \mu \mathrm{m}$ polyamide filter (Chromafil AO-20/25, Macherey-Nagel, Düren, Germany).

The extraction procedure and settings of the HPLCPDA Thermo Scientific Dionex UltiMate 3000 HPLC
(Thermo Scientific) system, combined with a TSQ Quantum Access Max quadrupole mass spectrometer (MS) (Thermo Fischer Scientific Institute, Waltham, MA, USA) system for capsaicinoids and spectrophotometric settings for total phenolics were based on Zamljen, Jakopič [19]. All data were expressed in $\mathrm{mg} / 100 \mathrm{~g}$ dry weight (DW).

\section{Statistical analysis}

Program R [20] was used for statistical analysis. The green algae treatment and amino acid treatment were both compared to the control treatment, using analysis of variance (ANOVA) and where statistically significant differences were present the LSD test was performed. The significant level was $\alpha \leq 0.05$. The error degree of freedom was 12 in all treatments.

\section{Results}

\section{Dry matter}

The average dry matter of each treatment is presented in Table 1 . The only significant differences were present with 'Habanero Red Caribbean' placenta (all other treatments were not significant), in which the amino acid treatment gave $2.0 \%$ less dry matter. Algae extract had a significant impact on seed dry matter in 'Somborka', with $10.0 \%$ more dry matter than in the control treatment and $9 \%$ than in the amino acid treatment.

\section{Sugar content}

Both biostimulants had a negative effect on glucose and fructose accumulation in the pericarp of 'Chilli AS-Rot' (Table 2) and on sucrose accumulation in 'Habanero Red Caribbean'. Amino acid treatment had a positive effect on sucrose accumulation in 'Somborka' pericarp, with an approximate increase of $25 \%$. In the placenta of 'Habanero Red Caribbean', glucose and fructose were

Table 1 Dry weight (\%; mean \pm SE) of three Capsicum cultivars (three fruit parts) treated with amino acids and green algae extract

\begin{tabular}{|c|c|c|c|c|c|c|c|}
\hline Treatment & \multicolumn{2}{|l|}{ Control (\%) } & \multicolumn{2}{|l|}{ Green algae (\%) } & \multicolumn{3}{|c|}{ Amino acids (\%) } \\
\hline \multicolumn{8}{|c|}{ 'Chilli AS-Rot' } \\
\hline Pericarp & 12.2 & & 12.6 & & 12.2 & & NS \\
\hline Placenta & 13.7 & & 13.2 & & 12.4 & & NS \\
\hline Seeds & 53.2 & & 51.8 & & 54.1 & & NS \\
\hline \multicolumn{8}{|c|}{ 'Habanero Red Caribbean' } \\
\hline Pericarp & 10.5 & & 11.6 & & 10.1 & & NS \\
\hline Placenta & 12.2 & $a^{\star}$ & 12.3 & a & 10.2 & $\mathrm{~b}$ & $* *$ \\
\hline Seeds & 37.9 & $a b$ & 42.6 & a & 29.1 & $b$ & $* *$ \\
\hline \multicolumn{8}{|l|}{ 'Somborka' } \\
\hline Pericarp & 6.5 & & 6.1 & & 6.7 & & NS \\
\hline Placenta & 7.2 & & 8.6 & & 8.2 & & NS \\
\hline Seeds & 15.7 & $b$ & 25.0 & a & 16.6 & $b$ & $* * *$ \\
\hline
\end{tabular}

a,b different letters denote statistical significant differences $(a \leq 0.05)$ between different biostimulant treatments in the same cultivar and fruit part 


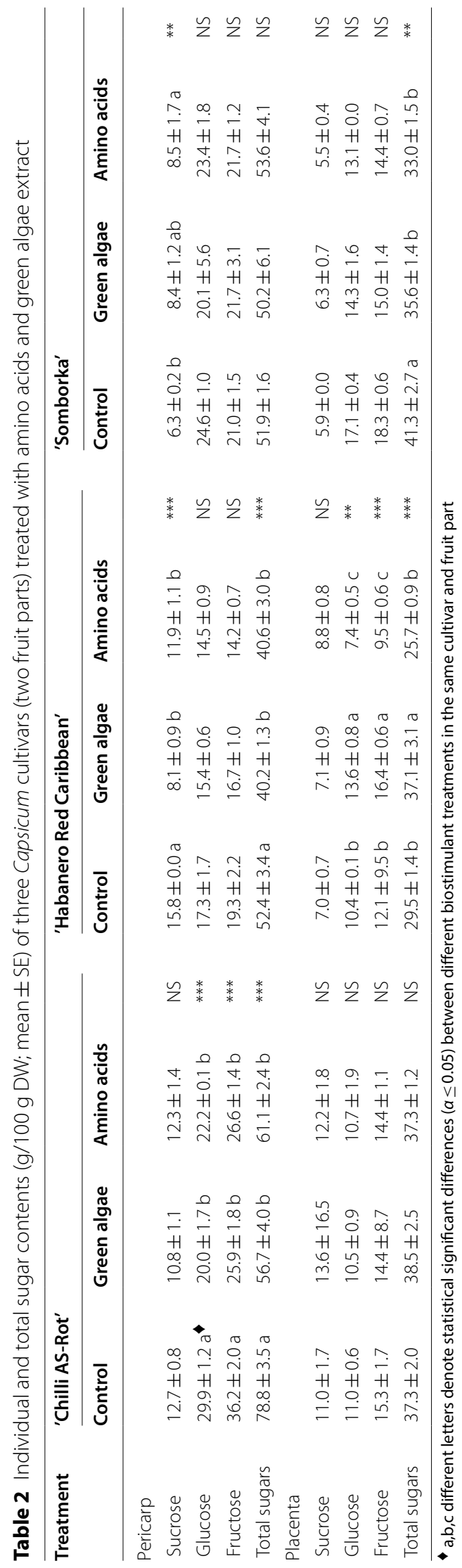


positively affected by green algae extract treatment, with an increase of $23.5 \%$ and $26.2 \%$, respectively. In the other two cultivars, there were no significant effects on the accumulation of individual sugars in placenta. Total sugar content was negatively affected by green algae extract and amino acids in pericarp in 'Chilli AS-Rot' and 'Habanero Red Caribbean' cultivars. On the other hand, in placenta of 'Habanero Red Caribbean', there was a 20.5\% increase of total sugars in the algae treatment compared to the control.

\section{Organic acid content}

Both biostimulants had a negative effect on oxalic acid content in pericarp of 'Chilli AS-Rot' and 'Somborka', while the amino acid treatment had a positive effect on oxalic acid content in 'Habanero Red Caribbean' (Table 3). Both biostimulants increased citric acid content in 'Somborka' pericarp, by approximately twofold. Amino acid treatment had a significant effect on quinic acid and succinic acid content in 'Habanero Red Caribbean' pericarp, with an increase of $37.9 \%$ and $21.5 \%$, respectively. The amino acid treatment also increased the fumaric acid content fivefold in 'Somborka' pericarp. The placenta was less affected by both biostimulant treatments (Table 3), with the only changes being in 'Habanero Red Caribbean' malic acid and succinic acid contents, whereby the amino acid treatment had the most noticeable effect. Succinic acid content also changed in 'Somborka' placenta, whereby both biostimulants had a negative effect on its content. Algae extract had a negative effect on total organic acid content in the placenta of 'Somborka', with a decrease of $3.9 \mathrm{~g} / 100 \mathrm{~g}$ DW. Total organic acid content in pericarp and placenta was positively affected by amino acid application in 'Habanero Red Caribbean'. The ascorbic acid content in 'Chilli AS-Rot' pericarp (Table 3) decreased by $22.1 \%$ in the green algae treatment. On the other hand, green algae and amino acid treatments had a positive effect on the ascorbic acid content in 'Somborka' pericarp. Green algae extract increased the ascorbic acid content by $20.8 \%$. In placenta of 'Somborka', foliar application of amino acids gave a significant increase (560.4 $\mathrm{mg} / 100 \mathrm{~g} \mathrm{DW})$ in ascorbic acid compared to the control (179.1 mg/100 g DW).

\section{Total phenolic content}

Total phenolic content (Table 4) in 'Chilli AS-Rot' pericarp was significantly higher in both biostimulant treatments. 'Habanero Red Caribbean' increased the total phenolic content in placenta by $619.9 \mathrm{mg} / 100 \mathrm{~g}$ DW in the algae extract treatment and by $834.1 \mathrm{mg} / 100 \mathrm{~g} \mathrm{DW}$ in the amino acid treatment, compared to the control. Amino acids also increased the total phenolic content in 'Habanero Red Caribbean' seeds by $36 \%$ compared to the control. Green algae extract and amino acids also had a positive effect on total phenolic content in 'Somborka' pericarp, with an approximate increase of $17 \%$ compared to the control.

\section{Capsaicinoids contents}

Amino acid treatment increased all capsaicinoid contents except for dihydrocapsaicin in the pericarp of 'Chilli ASRot' (Table 5) compared to the control treatment. Algae extract statistically significantly increased all capsaicinoid contents in 'Somborka' pericarp, with a total increase of $37.4 \mathrm{mg} / 100 \mathrm{~g}$ DW compared to the control treatment (Table 5). In the placenta, algae extract had a negative effect on total capsaicinoid contents in 'Chilli AS-Rot', with a $33.4 \%$ lower content than with the control treatment (Table 5). In 'Somborka', algae extract had a positive effect on total capsaicinoid accumulation in placenta, with higher contents compared to the control and amino acid treatments (748.1 mg/100 g DW and $414.2 \mathrm{mg} / 100 \mathrm{~g}$ DW, respectively). Green algae extract also caused a significant increase in the accumulation of capsaicinoids in 'Habanero Red Caribbean' placenta, with a 13.2\% increase compared to the control treatment. Application of amino acids had a negative effect on the total capsaicinoid contents in the placenta of 'Habanero Red Caribbean'. Both biostimulants had a positive effect on 'Somborka' seeds in terms of capsaicinoids, with $67.4 \mathrm{mg} / 100 \mathrm{~g}$ DW higher contents for algae extract and $61.1 \mathrm{mg} / 100 \mathrm{~g}$ DW for amino acid (Table 5).

\section{Discussion}

Foliar application of amino acids can improve plant dry matter, as previously reported by Abdelhamid, Sadak [21] in broad beans (Vicia faba L.). Dry matter was positively affected by amino acid applications in broccoli, improving its quality [22]. The results of Abdelhamid, Sadak [21] and Shekari and Javanmardi [22] differ from our results, since they do not show any positive impact of amino acids on the dry matter of various peppers. Our results showed an increase in dry matter (with green algae extract) of 'Habanero Red Caribbean' placenta and 'Somborka' seeds, which agrees with the results of Plaza, Gómez-Serrano [23] in which five-time foliar application of algae extracts noticeably improved Petunia $\times$ hybrid flower quality. On the other hand, Schwarz, Krienitz [24] could not confirm that algae extracts have a significant impact on lettuce and cucumber growth and quality. We observed lower dry matter in the cultivar 'Somborka', which could be due to the time of harvest. The other two cultivars were harvested at biological maturity and 'Somborka' was harvested at full size but not at biological maturity, resulting in lower dry matter, which was previously reported by Kołton, Wojciechowska [25]. The 


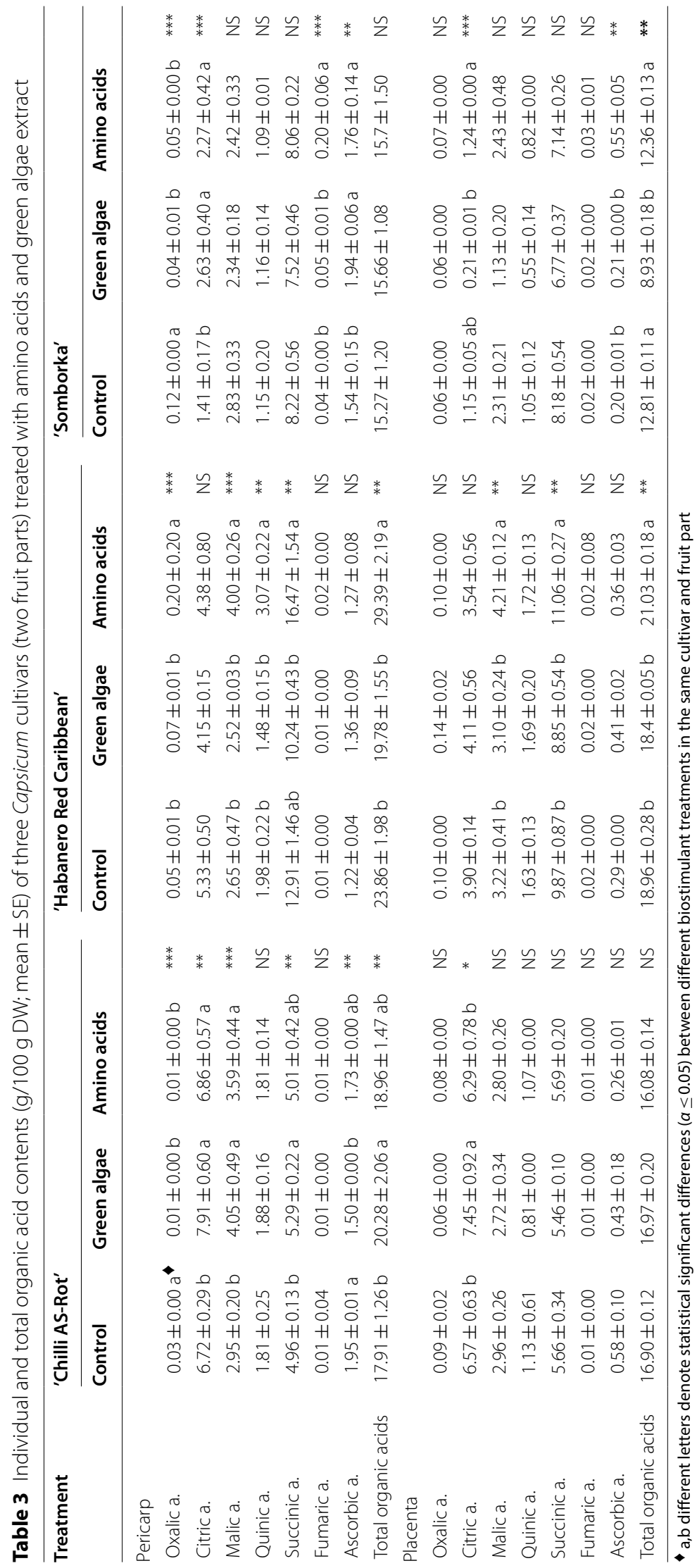




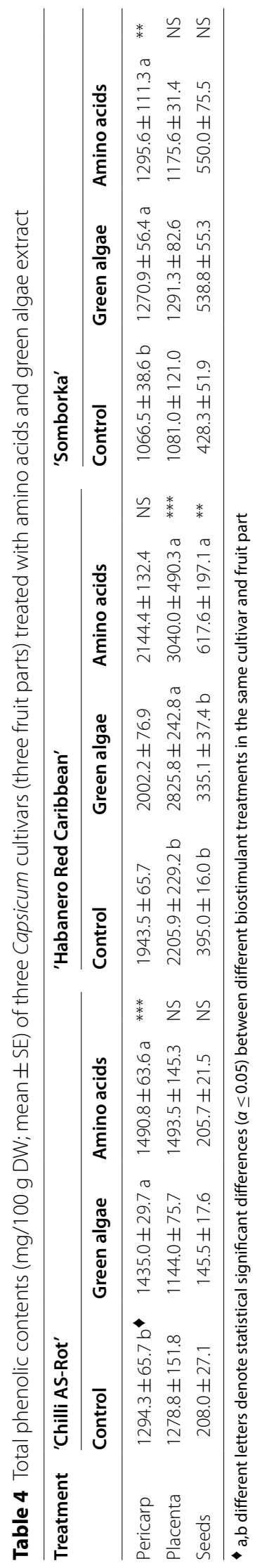




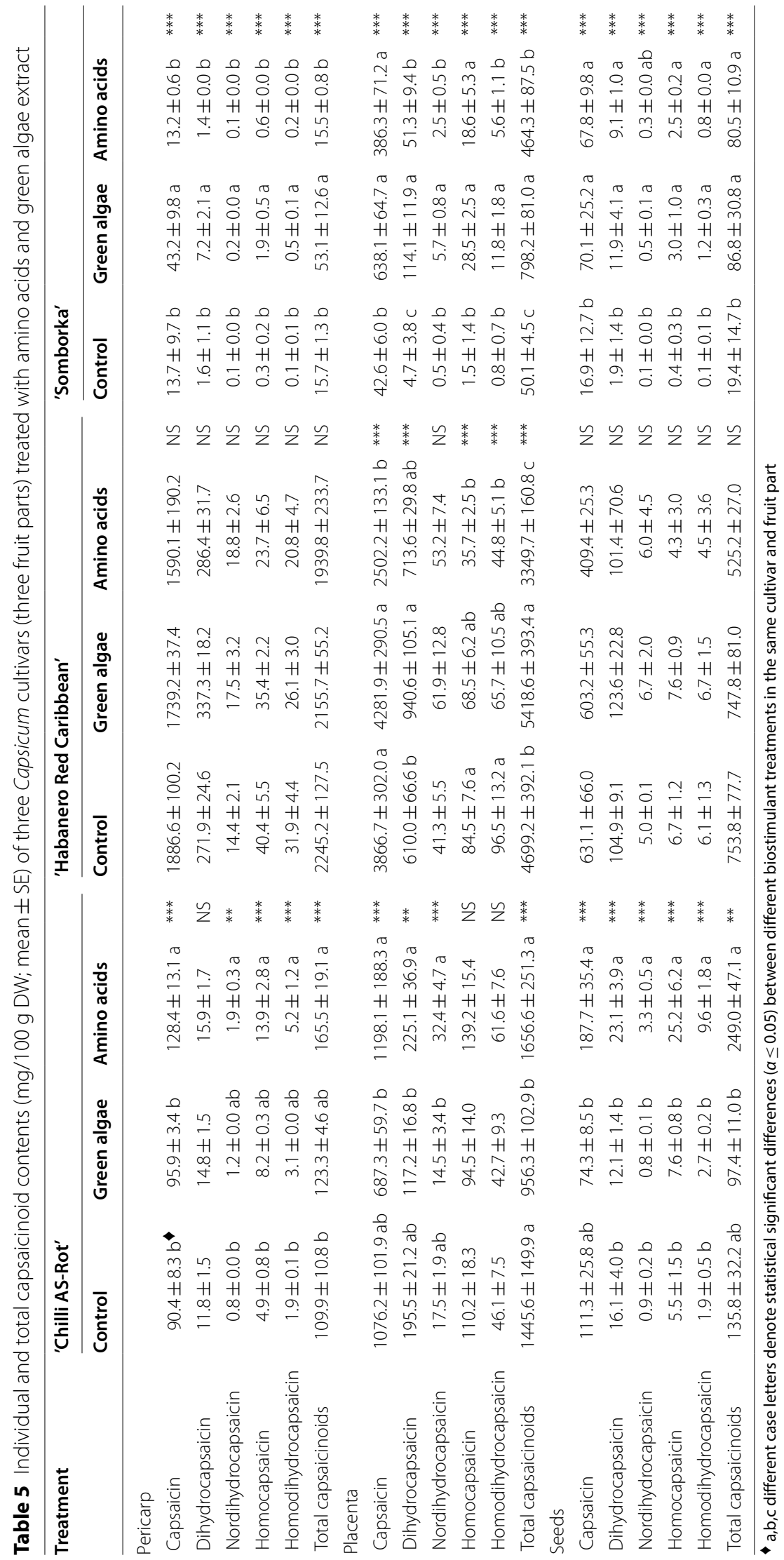


variability between treatments in terms of dry matter is mainly influenced by cultivar, which is also reported by Francesca, Arena [26] in tomato. Green algae extract had a positive effect, with differences observed, and amino acids had a negative effect only in one treatment. A possible reason for the positive effect of the algal extract on dry matter could be its content of hormones and other substances not present in the amino acid biostimulant. One of the hormones that affects cell division, growth and development are auxins [27], which could be the reason for the higher dry matter content, as larger cells and in larger amounts have more cell walls, cell organelles, etc., all of which contribute to higher dry matter values.

Amino acids did not in our case have an effect on higher sugar content, which contrasts with the report of García Gaytán, Díaz-Pérez [28], in which 'Jalapeño' pepper sugar content was positively affected by amino acid application. A positive effect of amino acids and algae extract was also previously reported by Ramya, Nagaraj [29] in Cyamopsis tetragonoloba L. and by Shehata, Abdel-Azem [30] in celeriac plant. Algae extract had a positive effect on total sugar content in the placenta of 'Habanero Red Caribbean', which agrees with the results of El-Sharony, El-Gioushy [31], who reported that a $2 \%$ algae foliar application increased total sugar content of mango fruits between 13 and 18\%. The lower sugar contents in certain treatments with amino acids and algae could be the result of higher enzyme activity, especially the activity of PAL (phenylalanine ammonia lyase) enzyme [32]. Sugars are used as primal substrates for further chemical reactions and synthesis of metabolites in plants [33]. If biostimulants stimulate enzymes then sugars are intensively used for synthesis of other metabolites such as phenols and would explain lower sugar content in our case. Glucose contents decreased in pericarp of 'Chilli AS-Rot' and 'Somborka' which was previously reported by Ertani, Francioso [15] in Zea mays, where they report that glucose could be used up by the plants for respiration process in order to produce more ATP for active nutrient transport, which is higher in sea weed treated plants $[15,17]$.

Algae extract in our study had a mostly negative effect on organic acid content, which is not in agreement with a study by Maraei, Eliwa [34], who reported that bell peppers had a higher organic acid content than the control. Amino acid treatment, on the other hand, had a mostly positive effect on organic acids, especially in the pericarp of 'Habanero Red Caribbean'. Similar results were previously reported by Khan, Hafiz [35], whereby amino acids also increased the organic acid content of hot peppers. Similar to our results, an effect of algae extracts and amino acid extracts on organic acid contents, such as ascorbic acid, was previously reported by Chooneea,
Boodia [36] and Khan, Hafiz [35], whereby both biostimulants increased the ascorbic acid content in bell peppers. Similar to our results, application of three amino acids (L-methionine, L-glycine and L-tryptophan) had no effect on ascorbic acid content, as previously reported by Khan, $\mathrm{Yu}$ [37] on lettuce. In some treatments, amino acids had a negative effect on ascorbic acid compared to the control. Ascorbate peroxidase (APX) reduces peroxide by converting ascorbic acid to dihydroascorbate. Algae extracts had a positive effect on APX enzyme activity in plants, since it helps them to reduce the negative effect of peroxide on the plant [38], which would explain the significantly higher ascorbic acid content in algae extract treated plants.

Mansori, Chernane [38] reported that algae extracts had a significant impact on total phenolic content in bean plants and Lola-Luz, Hennequart [39] reported a twofold increase in total phenolic content in algae-treated plants, which agrees with our results. Algae extracts increased cowpea (Vigna unguiculata L.) total phenolic content and influenced its growth and development [40]. Our results show that amino acids have a positive effect on the biosynthesis of phenolic compounds, although this effect is not present in all tissues and cultivars. Similar results were reported by Kałużewicz, Gąsecka [41] in broccoli plants and in sweet basil reported by Koca and Karaman [42]. Amino acids and algae extract have a significant impact on enzyme activity, which would explain the increased values of total phenolics. Since enzymes such as PAL need amino acids to create other substances, we help these enzymes by applying the extracts, saving the plants a lot of energy. PAL enzyme activity is increased with the addition of algae or amino acid extracts, since the PAL enzyme is the most important enzyme for the synthesis of polyphenols [38].

The results of capsaicinoid analysis showed that amino acid treatment had a positive effect on total capsaicinoids and individual capsaicinoids accumulation in pericarp and placenta of 'Chilli AS-Rot' and in placenta and seeds of 'Somborka', which agrees with the results of Hammam, Eisa [43], who reported an increase in capsaicin in hot peppers after amino acid application. Interestingly, the amino acid treatment decreased the capsaicinoid content in 'Habanero Red Caribbean' placenta. A possible reason for this is that the concentrations of amino acids were too high for this particular species. Nardi, Pizzeghello [44] reported that several biostimulants had no effect or even a negative effect on plants if the concentrations or application rates were too high. The effects of algae extracts on individual and total capsaicinoid contents are poorly reported in previous studies. In our study, green algae extract had a positive effect on 'Somborka' pericarp and seeds and 'Habanero Red Caribbean' placenta. Since 
algae extracts contain many substances that could benefit or even perhaps negatively affect the capsaicinoid content in plants, it is difficult to pinpoint exactly which substance is the main factor that impacts the synthesis [45]. Similar as with phenolics, capsaicinoid content is mostly related to the activity of enzymes such as PAL [38], which is stimulated by biostimulants.

We observed a different effect of the two biostimulants depending on the variety cultivar. In some cases, we observed a decrease in metabolite content and in others an increase. A biostimulant must enter the plant through the leaves or roots, depending on the application [46]. Different species or cultivars have different leaf permeability for the biostimulants, which would explain our results with different responses in terms of metabolites in cultivars [47]. Absorption of biostimulants depends on field conditions, especially water availability, fertilization and temperature [48]. A barrier to the uptake of biostimulants may be the leaf cuticle or the chemical structure of the bioactive compound itself [49]. The cuticle is composed of various cuticular waxes and polymers such as cutin and cutan [50]. The presence of the cuticle and its thickness and texture is species specific and can influence the functionality and effectiveness of the biostimulant [51]. Capsicum plants have a relatively thick cuticle composed of lipids and cutin monomers [52]. The thickness of the cuticle is cultivar and species specific, which would explain why 'Habanero Red Caribbean' was less affected by the biostimulant treatments than the other two cultivars, as it is a different Capsicum species.

Both biostimulants have a different structure. The algal extract contains less nitrogen and carbon compared to the amino acid biostimulant. The other substances are also in lower contents in algae extract, which is in some cases better since to high concentrations can be phytotoxic for plants [44]. In our case, the concentrations of biostimulants could be too high for optimal synthesis of certain metabolites, like sugars and for certain species or cultivars, that is the reason why we got not effect or even negative effects.

\section{Conclusion}

We analyzed two biostimulants (green algae and amino acids) and their effect on the quality of the fruits of three chili cultivars. Overall, our study indicates major variability among all three cultivars. Interestingly, the overall effect of biostimulants had a greater impact on the less pungent cultivars, 'Chilli AS-Rot' and 'Somborka', showing an interesting perspective on how different cultivars can react in very different ways to biostimulant application. Both biostimulants had a different effect in all three fruit parts. The best proved to be the amino acid biostimulant, with a significant increase in most metabolites although its effectiveness was varying based on cultivar and fruit part. 'Chilli AS-Rot' fruits in particular greatly benefited from it. Green algae extract proved to be less effective with 'Chilli AS-Rot' and 'Habanero Red Caribbean' but had a major impact on the 'Somborka' capsaicin content. Our study shows that not all biostimulants can be used on every cultivar, since they do not affect all species and cultivars in the same way. For production on farms, farmers should test different plant stimulants to determine on which species or cultivar they work best, the appropriate amount of applications, time of applications and the effect on capsaicinoids contents, saving them a lot of money and resulting in the best quality yield.

\section{Acknowledgements}

This work is part of the program Horticulture P4-0013-0481 supported by the Slovenian Research Agency.

\section{Authors' contributions}

Conceptualization: TZ, AS; Experiment and methodology: TZ, AS; Statistical analysis: TZ; Writing of manuscript: TZ; Supervision, review of manuscript: AS, $\mathrm{RV}, \mathrm{MH}$; Funding: RV, MH. All authors read and approved the final manuscript.

\section{Funding}

This work is part of the program Horticulture P4-0013-0481 supported by the Slovenian Research Agency.

\section{Availability of data and materials}

The datasets used and/or analyzed during the current study are available from the corresponding author on reasonable request.

\section{Declarations}

Ethics approval and consent to participate

This manuscript is an original paper and has not been published in other journals. The authors agreed to keep the copyright rule.

Consent for publication

The authors agreed to the publication of the manuscript in this journal.

\section{Competing interests}

The authors declare that they have no competing interests.

Received: 9 August 2021 Accepted: 28 September 2021

Published online: 10 November 2021

References

1. Bley K, Boorman G, Mohammad B, McKenzie D, Babbar S. A comprehensive review of the carcinogenic and anticarcinogenic potential of capsaicin. Toxicol Pathol. 2012;40(6):847-73.

2. Yoneshiro T, Aita S, Kawai Y, Iwanaga T, Saito M. Nonpungent capsaicin analogs (capsinoids) increase energy expenditure through the activation of brown adipose tissue in humans. Am J Clin Nutr. 2012;95(4):845-50.

3. McCarty MF, DiNicolantonio JJ, O'Keefe JH. Capsaicin may have important potential for promoting vascular and metabolic health. Open Heart. 2015;2(1): e000262.

4. Diepvens K, Westerterp KR, Westerterp-Plantenga MS. Obesity and thermogenesis related to the consumption of caffeine, ephedrine, capsaicin, and green tea. Am J Physiol Regul Integr Comp Physiol. 2007;292(1):R77-85. 
5. Naves ER, de Ávila SL, Sulpice R, Araújo WL, Nunes-Nesi A, Peres LEP, et al. Capsaicinoids: pungency beyond Capsicum. Trends Plant Sci. 2019;24(2):109-20.

6. Arrowsmith S, Egan TP, Meekins JF, Powers D, Metcalfe M. Effects of salt stress on capsaicin content, growth, and fluorescence in a jalapeno cultivar of Capsicum annuum (Solanaceae). Bios. 2012;83(1):1-7.

7. Gutiérrez-Carbajal MG, Monforte-González M, de L Miranda-Ham M, Godoy-Hernández G, Vázquez-Flota F. Induction of capsaicinoid synthesis in Capsicum chinense cell cultures by salicylic acid or methyl jasmonate. Biologia plantarum. 2010;54(3):430-4.

8. Zheng F, Chen L, Zhang P, Zhou J, Lu X, Tian W. Carbohydrate polymers exhibit great potential as effective elicitors in organic agriculture: a review. Carbohydr Polym. 2020;230: 115637.

9. Shams M, Yildirim E, Ekinci M, Agar G, Turan M, Kul R. Exogenous cytokinin application increased the capsaicin and ascorbic acid content in pepper fruit. Sci Papers. 2018;62:507-11.

10. Pizzeghello D, Schiavon M, Francioso O, Vecchia FD, Ertani A, Nardi S. Bioactivity of size-fractionated and unfractionated humic substances from two forest soils and comparative effects on $\mathrm{n}$ and $\mathrm{s}$ metabolism, nutrition, and root anatomy of Allium sativum L. Front Plant Sci. 2020;11: 1203.

11. Popko M, Michalak I, Wilk R, Gramza M, Chojnacka K, Górecki H. Effect of the new plant growth biostimulants based on amino acids on yield and grain quality of winter wheat. Molecules. 2018;23:470.

12. Abd E, Abd-Allah A. Effect of green alga cells extract as foliar spray on vegetative growth, yield and berries quality of superior grapevines. J Agric Environ Sci. 2008:4:427-33.

13. Calvo P, Nelson L, Kloepper JW. Agricultural uses of plant biostimulants. Plant Soil. 2014;383(1):3-41.

14. Chiaiese P, Corrado G, Colla G, Kyriacou MC, Rouphael Y. Renewable sources of plant biostimulation: microalgae as a sustainable means to improve crop performance. Front Plant Sci. 2018;9: 1782.

15. Ertani A, Francioso O, Tinti A, Schiavon M, Pizzeghello D, Nardi S. Evaluation of seaweed extracts from Laminaria and Ascophyllum nodosum spp. as biostimulants in Zea mays I. using a combination of chemical, biochemical and morphological approaches. Front Plant Sci. 2018;9:428

16. Satish L, Ramesh M. Algae-based extracts as a natural biostimulant for plant growth and development: current and futureprospects. In: Photobioreactors: advancements, applications and research. Hauppauge, NY, USA: Nova Science Publishers, Inc.; 2017. pp. 1-13.

17. Ertani A, Pizzeghello D, Francioso O, Sambo P, Sanchez-Cortes S, Nardi S. Capsicum chinensis L. growth and nutraceutical properties are enhanced by biostimulants in a long-term period: chemical and metabolomic approaches. Front Plant Sci. 2014;5: 375.

18. Park M-H, Lee J-S, Yang E-Y, Do G-R, Hong Y-P. Optimal harvest time for preventing hot pepper seed browning during cold storage is associated with seed maturity. Agriculture. 2020;10(12):585.

19. Zamljen T, Jakopič J, Hudina M, Veberič R, Slatnar A. Influence of intra and inter species variation in chilies (Capsicum spp.) on metabolite composition of three fruit segments. Sci Rep. 2021;11(1):4932.

20. RDCTTR: A language and environment for statistical computing. 2008

21. Abdelhamid M, Sadak M, Schmidhalter U. Effect of foliar application of amino acids on plant yield and some physiological parameters in bean plants irrigated with seawater. Acta Biológica Colombiana. 2014;20:140-52

22. Shekari $G$, Javanmardi J. Effects of foliar application pure amino acid and amino acid containing fertilizer on broccoli (Brassica oleracea L. var. italica) transplants. Adv Crop Sci Technol. 2017. https://doi.org/10.4172/23298863.1000280.

23. Plaza BM, Gómez-Serrano C, Acién-Fernández FG, Jimenez-Becker S. Effect of microalgae hydrolysate foliar application (Arthrospira platensis and Scenedesmus sp.) on Petunia $\times$ hybrida growth. J Appl Phycol. 2018;30(4):2359-65.

24. Schwarz D, Krienitz L. Do algae cause growth-promoting effects on vegetables grown hydroponically? In: Price MR (ed) Fertigation: optimizing the utilization of water and nutrients. Beijing: International Potash Institute; 2005. pp. 161-70.

25. Kotton A, Wojciechowska R, Leja M. Effect of maturity stage and shortterm storage on the biological quality of sweet pepper fruits. Veg Crop Res Bull. 2011. https://doi.org/10.2478/v10032-011-0012-8.

26. Francesca S, Arena C, Hay Mele B, Carlo S, Ambrosino P, Barone A, et al. The use of a plant-based biostimulant improves plant performances and fruit quality in tomato plants grown at elevated temperatures. Agronomy. 2020;10:363.

27. de Vasconcelos ACF, Chaves LHG. Biostimulants and their role in improving plant growth under abiotic stresses. In: Mirmajlessi SM, Radhakrishnan R, editors. Biostimulants in plant science. London: IntechOpen; 2019. p. 1-14.

28. García Gaytán V, Díaz-Pérez J, Bautista J, Gunawan G, Bateman A, GómezMerino F. Exogenous applications of amino acids affect the growth and concentration of chlorophylls, amino acids and sugars in jalapeño pepper (Capsicum annuum L.) fruit. HortScience. 2018;53:488-9.

29. Ramya S, Nagaraj S, Vijayanand N. Biofertilizing efficiency of brown and green algae on growth, biochemical and yield parameters of Cyamopsis tetragonolaba (L.) Taub. Rec Res Sci Tech. 2010;2:45-52.

30. Shehata S, Abdel-Azem H, Abou El-Yazied A, El-Gizawy A. Effect of foliar spraying with amino acids and seaweed extract on growth chemical constitutes, yield and its quality of celeriac plant. Eur J Sci Res. 2011;58:257-65.

31. El-Sharony TF, El-Gioushy S, Oa A. Effect of foliar application with algae and plant extracts on growth, yield and fruit quality of fruitful mango trees Cv. Fagri Kalan. J Hortic. 2015;2:162.

32. Turan M, Yildirim E, Ekinci M, Argin S. Effect of biostimulants on yield and quality of cherry tomatoes grown in fertile and stressed soils. HortScience. 2021;56:1-10.

33. Ciereszko I. Regulatory roles of sugars in plant growth and development. Acta Soc Bot Pol. 2018. https://doi.org/10.5586/asbp.3583.

34. Maraei R, Eliwa N, Aly A. Use of some biostimulants to improve the growth and chemical constituents of sweet pepper. Potr S J F Sci. 2019;13(1):553-61.

35. Khan R, Hafiz I, Shafique M, Ishaq A, Qureshi AA. Effect of pre-harvest foliar application of amino acids and seaweed (Ascophylum nodosum) extract on growth, yield, and storage life of different bell pepper (Capsicum annuum L.) cultivars grown under hydroponic conditions. J Plant Nutr. 2018;41:1-11.

36. Chooneea Y, Boodia N, Chandrabose S. Effect of naturally occurring amino acid stimulants on the growth and yield of hot peppers (Capsicum annum L.). J Anim Plant Sci. 2009:5:414-24.

37. Khan $S$, Yu H, Li Q, Gao Y, Sallam BN, Wang H, et al. Exogenous application of amino acids improves the growth and yield of lettuce by enhancing photosynthetic assimilation and nutrient availability. Agronomy. 2019;9(5):266.

38. Mansori M, Chernane H, Latique S, Benaliat A, Hsissou D, El Kaoua M. Seaweed extract effect on water deficit and antioxidative mechanisms in bean plants (Phaseolus vulgaris L.). J Appl Phycol. 2015;27(4):1689-98.

39. Lola-Luz T, Hennequart F, Gaffney M. Enhancement of phenolic and flavonoids compounds in cabbage (Brassica oleraceae var italica) following application of commercial seaweed extracts of the brown seaweed, Ascophyllum nodosum. Agric Food Sci. 2013;22:288-95.

40. Vasantharaja R, Abraham LS, Inbakandan D, Thirugnanasambandam $\mathrm{R}$, Senthilvelan $\mathrm{T}$, Jabeen SKA, et al. Influence of seaweed extracts on growth, phytochemical contents and antioxidant capacity of cowpea (Vigna unguiculata L. Walp). Biocatal Agric Biotechnol. 2019;17:589-94.

41. Kałużewicz A, Gąsecka M, Spiżewski T. Influence of biostimulants on phenolic content in broccoli heads directly after harvest and after storage. Folia Hortic. 2017. https://doi.org/10.1515/fhort-2017-0020.

42. Koca N, Karaman S. The effects of plant growth regulators and L-phenylalanine on phenolic compounds of sweet basil. Food Chem. 2015:166C:515-21.

43. Hammam KA, Eisa EA, Dewidar AA. Effect of organic fertilization and amino acids on growth, chemical composition and capsaicin content of hot pepper (Capsicum annum L var. Minimum) plant. APRJ. 2020. https:// doi.org/10.9734/aprj/2020/v6i430136.

44. Nardi S, Pizzeghello D, Schiavon M, Ertani A. Plant biostimulants: physiological responses induced by protein hydrolyzed-based products and humic substances in plant metabolism. Sci Agric. 2016;73:18-23.

45. Dang TT, Bowyer MC, Van Altena IA, Scarlett CJ. Comparison of chemical profile and antioxidant properties of the brown algae. Int J Food Sci Technol. 2018;53(1):174-81.

46. Parađiković N, Teklić T, Svjetlana Z, Lisjak M, Špoljarević M. Biostimulants research in some horticultural plant species - a review. Food Energy Secur. 2018. https://doi.org/10.1002/fes3.162. 
47. Bulgari R, Cocetta G, Trivellini A, Vernieri P, Ferrante A. Biostimulants and crop responses: a review. Biol Agric Hortic. 2015;31:1-17.

48. Kolomazník K, Pecha J, Friebrová V, Janáčová D, Vašek V. Diffusion of biostimulators into plant tissues. Heat Mass Transf. 2012;48(9):1505-12.

49. Pecha J, Fürst T, Kolomazník K, Friebrová V, Svoboda P. Protein biostimulant foliar uptake modeling: the impact of climatic conditions. AIChE J. 2012;58(7):2010-9.

50. Schreiber L. Polar paths of diffusion across plant cuticles: new evidence for an old hypothesis. Ann Bot. 2005:95(7):1069-73.

51. Liao C-Y, Chen M-Y, Chen Y-K, Kuo K-C, Chung K-R, Lee M-H. Formation of highly branched hyphae by Colletotrichum acutatum within the fruit cuticles of Capsicum spp. Plant Pathol. 2012;61 (2):262-70.
52. Parsons E, Popovsky S, Lohrey G, Alkalai-Tuvia S, Perzelan Y, Bosland P, et al. Fruit cuticle lipid composition and water loss in a diverse collection of pepper (Capsicum). Physiol plantarum. 2013. https://doi.org/10.1111/ ppl.12035.

\section{Publisher's Note}

Springer Nature remains neutral with regard to jurisdictional claims in published maps and institutional affiliations.

\section{Submit your manuscript to a SpringerOpen ${ }^{\circ}$ journal and benefit from:}

- Convenient online submission

- Rigorous peer review

- Open access: articles freely available online

- High visibility within the field

- Retaining the copyright to your article

Submit your next manuscript at $\boldsymbol{\nabla}$ springeropen.com 